Journal of Social Sciences 7 (2): 120-126, 2011

ISSN 1549-3652

(C) 2010 Science Publications

\title{
How Guanxi Relates to Social Capital? A Psychological Perspective
}

\author{
${ }^{1}$ Kai-Ping Huang and ${ }^{2}$ Karen Yuan Wang \\ ${ }^{1}$ School of Management, University of Technology, Sydney, Australia \\ PO Box 123, Broadway NSW 2007, Australia \\ ${ }^{2}$ School of Management, University of Technology, Sydney, Australia \\ PO Box 123, Broadway NSW 2007, Australia
}

\begin{abstract}
Problem statement: The study aims to offer a discussion on social capital and guanxi, in order to illustrate the similarities and differences between these two concepts and how Chinese guanxi varies from Western preconceptions concerning social networking. Approach: The literature review and arguments were conducted to provide a systematic discussion of the guanxi and social capital relationship. Results: Both guanxi and social capital involve social relations; it is important to appreciate that guanxi does not relate exclusively to social capital, or that guanxi itself is simply another term for social capital. Conclusion: Both guanxi and social capital are similar concepts. Social capital is considered as both the attributes of individuals and organizations; thus, guanxi is distinctively about interpersonal relationships, which are often lost within the corporate environments of large organizations.
\end{abstract}

Key words: Guanxi and social capital, social relationship, psychological perspective, cultural perspective, unique characteristic, institutional perspective, dyadic perspective, Chinese entrepreneurs, guanxi-based relationship, interpersonal relationship

\section{INTRODUCTION}

Recently, social capital has been recognized as a significant issue to success in organizational activities (Bernardes, 2010). Judgment on social capital varies from one to another. For instance, Burt (1992) defines social capital as opportunities that every individual can receive by building relationships with others. Also, Coleman (1998) has argued that social capital not only relationship but values and norms. Based on these views, it can be seen that social capital focuses greatly on relationships and these relationships can help organizations to generate trust and value.

Correspondently, many social researchers have focused on guanxi, which has been translated in different ways, such as social relationship and personal relationship. Some studies have made guanxi the main concept of research (Guthrie, 1998; Tsang, 1998; Luo, 2007). In Chinese language, guanxi basically refers to social connections or relationships based on reciprocal interests and benefits (Bian, 1994; Yang, 1994). Some studies have pointed out that guanxi is a form of social capital (Luo, 2007; Wong, 2000), but a systematic discussion of the two concepts has not been conducted yet. This study is trying to provide a general blueprint in relation to these two concepts. Further research would be needed to have more analysis that is specific on each of them.

\section{MATERIALS AND METHODS}

The study is to provide several constructs and discussions in relation to guanxi and social capital based on the following literature review:

Concept of guanxi: The research of guanxi can be approached from many perspectives. For example, from cultural perspective, guanxi is a unique characteristic in Chinese culture Perks et al., 2009). Moreover, from institutional perspective, guanxi is a product of unripe legal and regulatory structure (Guthrie, 2002). On the surface, guanxi, the Chinese general term, is commonly defined as relationship between two people (Fan, 2002). Jacob (1979) defines guanxi in its traditional concept as direct particularistic ties. However, in Chinese society, it has another deep meaning beneath. Relationship has been seen as an end in themselves (Hong and Engestrom, 2004). Chinese have much stronger tendency to divide people into categories and treat them accordingly. Consequently, Fan (2002) argued that

Corresponding Author: Kai-Ping Huang, School of Management, University of Technology, Sydney, Australia, PO Box 123, Broadway NSW 2007, Australia 
though guanxi and relationship are similar, guanxi might not be created by relationships. For example, both A and B work in the same organization. Colleague is the relationship between them, yet guanxi might not exist. From this point of view, there is no word in English which has an exact interpretation (Fan, 2002).

Generally, guanxi is more than the exchanging of gifts in order to procure favorable business exchange. Luo and Chen (1996) observe, "many Western business people are often in danger of overemphasizing the giftgiving and wining-and-dining components of a guanxi relationship, thereby coming dangerously close to crass bribery or to being perceived as meat and wine friends, " which is a Chinese metaphor for mistrust. Guanxi rests on the cultivation of long-term personal relationships, a condition existing to some extent in every human society. However, Chinese guanxi is pervasive; it is distinct because it has a central role in daily social and business life.

The historical roots of guanxi can be traced back to the five cardinal relationships (wu lun) embedded in Confucian philosophy. The primary relationships are the dyadic parallel between ruler and subject, father and son, husband and wife, elder brother and younger brother and friend and friend (Chen and Chen, 2004). There is likewise a dyadic structure within guanxi. Chen and Chen (2004) argue that, "By taking a dyadic perspective, we do not mean to suggest that the Chinese do not form networked groups but rather that those network groups have interpersonal guanxi dyads as their fundamental units." Networks constitute an important aspect of guanxi-based business practices. Guanxi is, however, fundamentally embedded in the interpersonal relationship between two individuals (Zhuang et al., 2010; Fan, 2002).

Guanxi and chinese negotiation style: Guanxi is often based on a symbolic gesture, giving rise to an unpaid obligation (Pye, 1992). This unpaid obligation or Renqing is the first step in a series of exchanges, which ultimately lead to the formation of a guanxi-based relationship. Commonality can be established in a variety of ways. However, the existence of a commonality is necessary; but not sufficient condition for the formation of guanxi (Luo, 2007). There must be a reciprocal, substantive benefit than can possible arise from the relationship.

China's institutional private equity and venture capital market is similar to those of the United States and Europe, but one important distinction is that of guanxi. There is not the same degree of openness with strangers, or with those who are not integrated into the known social network of the business leaders as occurs in western countries. Many practices that are taken for granted in the West routine in China. To begin with, there is a lack of transparent information about opportunities, entrepreneurs and companies available publicly to entrepreneurs.

Chinese entrepreneurs sometimes value standardized regulations regarding finance, corporate structures and governance: they are more inclined to apply informal contractual obligations in keeping with guanxi that they have built up, sometimes over generations, through complex social networking. For foreigners striving for successful investment in China, knowledge and appreciation of the importance of social capital networks, or guanxi is vital. Without an understanding of guanxi, it is difficult to overcome obstacles to success in a number of areas: corporate governance and shareholder rights; the ability to manage intellectual property; the ability to adapt business models to local conditions; the ability to add managerial and technical value to young enterprises; knowledge of legal structure; and an ability to navigate complex regulatory environments (Gao et al., 2010)

But though guanxi is achieved at the interpersonal level, it is a complex relationship that cannot be assumed following a number of outwardly convivial meetings. There are eight elements that characterise Chinese negotiations. Westerners often find these elements obscure and manipulative; yet there is growing appreciation that a negotiation process that does not entail due observance of guanxi can fail to achieve a desirable deal; negotiations can easily fall apart.

Guanxi, or literally personal connections, is distinct from what Westerners put a premium on, being networking, information and institutions; instead the Chinese place a premium on individuals' social capital within their group of friends, relatives and close associates. Thus, the Zhongjian Ren or Intermediary (Graham and Lam, 2003), is vital to gaining even initial admission or introduction to connections (Chen and Chen, 2004). To some extent this need for the intermediary is the reverse of Western practice, where interlocutors tend to trust others until or unless given reason not to; where such trust is abused, there are remedies available through the courts and tribunals that more or less impartially apply torts or legislation designed to meet contingencies of fraud or broken contracts. But in China, suspicion and distrust characterize all meetings with strangers. Remedy through litigation is less readily available; where it is sought, the same conditions governing guanxi in business applies in law. Judges and other court officials will favour those with whom they have a relationship. This relationship may have come about because of a 


\section{J. Social Sci., 7 (2): 120-126, 2011}

gift, that would normally be construed as corruption or malversation in the West, but which is perfectly regular in a society where the precepts of guanxi are the established norms.

Another aspect of guanxi is that of Shehui Dengji or Social Status (Graham and Lam, 2003). Western casualness is often unwelcome, even grating when applied where Confucian values of obedience and deference to one's superiors remain strong. Formality has more than superficial meaning. Deference to rank and title has deeper significance in this society where recognition of status, is of profound importance in furthering guanxi. Such recognition can seem pretentious and ridiculously ritualistic to Westerners whose outward egalitarianism is fundamental to their professed democratic ideals. But Westerners who hope to succeed in business must be willing to acknowledge the superior wisdom of Shehui Dengji that is rooted in an ancient culture in this age of globalization and multiculturalism. Recognition of Shehui Dengji is one of the benefits afforded to Westerners by the diversity that right thinking people are only too happy to embrace.

Through going about Shehui Dengji in the right way, Renji Hexie or Interpersonal Harmony is achieved (Graham and Lam, 2003). Harmony transpires because the supplicant realises his place in the guanxi hierarchy. A successful interlocutor must appreciate the percipience of the Chinese sayings, " $\mathrm{A}$ man without a smile should not open a shop and sweet temper and friendliness produce money”. (Graham and Lam, 2003). Harmonious relations between business partners, even if there is no underlying goodwill, but simply an aspiration for a profitable, lucrative interaction, the profit motive in itself should be sufficient to engender suitable outward expression and a willingness to comply with the opportunity costs implicit in maintaining harmony (Park and Luo, 2001).

Guanxi also entails an overview of the business Zhengti Guannian or Holistic Thinking (Graham and Lam, 2003). The Chinese think in terms of the whole while Westerners think sequentially and individualistically, breaking up complex negotiation tasks into a series of smaller issues: price, quantity, warranty, delivery and so on (Graham and Lam, 2003) . Chinese negotiators are less focused on detail, in the belief that if guanxi is to be ongoing, then the details will be addressed in the course of the relationship. To Westerners though, it may seem that without carefully stipulated agreements, there is no surety of contractual satisfaction if the interpersonal relationship breaks down. Westerners dealing with Chinese businesses should grasp the merit of working to maintain guanxi, of imparting the utmost value to their social network, so that they too will prosper to the utmost.

Unlike affluent Westerners, Chinese businessmen are cost conscious. China's long history of economic and political instability has taught its people to save their money, a practice known as Jiejian (Graham and Lam, 2003). The realize savings, guanxi will often mean that the most enduring relationships are with those who are flexible in business negotiations, who are willing to engage bargaining over prices usually through haggling. Chinese social net-workers may pad their offers with more room to manoeuvre than most Westerners are used to and they will make concessions on price with great reluctance and only after lengthy discussions (Graham and Lam, 2003). But often such manoeuvres are an aspect of relating, a means to gain the measure of a new or prospective member of a network, or even a form of pleasantry that may seem duplicitous or challenging to the unaware. Westerners must learn to approach such negotiations with an openmind, even if they involve initial losses in the early phases of establishing guanxi.

It is difficult to achieve effective guanxi without Mianzi meaning "Face" (Buckley et al., 2006; Chueng and King, 2004). In Chinese business culture, a person's reputation and social standing rest on saving face. If Westerners cause the Chinese embarrassment or loss of composure, even unintentionally, business negotiations cannot succeed because it is no longer possible for the shamed interlocutor to interact with dignity (Graham and Lam, 2003; Ho and Redfern, 2010). Because guanxi is transferred interpersonally, individual links ultimately foster a network of relationships. Once immersed in a network, one maintains face or Mianzi by reciprocating favours. Face is fundamental for the development and maintenance of guanxi. The abstract concept of face is regarded by the Chinese as possible to be quantified and measured (Ho, 1976). One way to quantify the face of an individual depends on the person's guanxi network.

Failure to follow the rules of reciprocity and equity in a guanxi-based relationship leads to loss of face (Luo and Chen, 1996). Such loss ultimately manifests in intolerable degradation and possible dissolution of the guanxi relationship. Opportunities and outlets for exchange are lost with the loss of guanxi within a specific network participant. Individual relationships serve as the foundation of the guanxi network. Where loss of exchange opportunity occurs with a social network the offending interlocutor can easily suffer banishment from the network altogether. The looming threat of network ostracism provides a powerful 


\section{J. Social Sci., 7 (2): 120-126, 2011}

incentive for commitment to the individual exchange relationship (Standifird and Marshall, 2000), such that it is no necessary in such settings for ant resource to formal legal remedies. In some ways, the redundancy of courts and legislation that is so fundamental in the West recalls the village and rural economies that depended so heavily on trust between individuals.

To reap the benefits of guanxi, those engaged with Chinese social networks are expected to exercise Chiku Nailao, Endurance, Relentlessness, or Eating Bitterness and Enduring Labour (Graham and Lam, 2003; Rosato, 2005). Chinese networks expect reciprocity in joint projects, not merely the benefit of connections for their own sake. Diligence is often extended further to endurance (Yamagishi and Yamagishi, 1994). Where Westerners place high value on talent as a key to success, the Chinese see Chiku Nailao as much more important and honourable: to sustain one's place in a social network, members must be willing to undertake a range of tasks that range from menial to professional, without endangering the respect due one for one's education or social status. But to avoid Chiku Nailao can lead to loss of face and even exclusion from guanxi.

Guanxi can be translated in different ways, including social relationship and personal relationship (Guthrie, 1998; Tsang, 1998; Luo, 2007). In Chinese, the concept of guanxi embraces social connections or relationships based on reciprocal interests and benefits (Bian, 1994; Yang, 1994): often, its import depends on the social context and the assumptions upon which a social network is formed. Guanxi acts as a form of social capital (Luo, 2007; Wong, 2000), that brings concrete benefits and opportunities to earn benefits. There is then some disagreement as to the semantic purpose of guanxi.

\section{RESULTS AND DISCUSSION}

In any society, social capital needed for success in organizational activities. Understanding of the essence of social capital results in several defining components, not always consistent (Carifio, 2010). Thus, Burt (1992) defines social capital as opportunities open to individuals who cultivate relationships with others. Yet Coleman (1998) stipulates that social capital can only be realised where a relationship is complemented by similar values and norms. In either case, the purpose of social networking is to generate trust and value of the interaction facilitated by relationships (Standifird and Marshall, 2000), or in China, by guanxi. Importantly, this trust cannot be legislated to apply to a broader community, but depends on interpersonal relationships.

Guanxi can be approached as a variant of Bourdieu's concept of social capital. Bourdieu (1986) identified three forms of social resource: economic, cultural and social capital. Social resources in guanxi convey an interlocutor's social position and the contacts available to him through networking. To derive the ultimate gain from social capital, it is crucial to maintain face or Mianzi. Hence, social capital has two components: it is primarily connected with group membership and social networks. But just as importantly, social capital is $\mathrm{s}$ mutual sustained by mutual cognition and recognition. Bourdieu, in his more generalised theory on social capital, argues that enduring benefits continue where respect, appreciation and friendship are manifest.

In some social contexts, there is a presumption of entitlement, there are guaranteed rights from one's own family, class and school or country of citizenship, though the larger the organisation, the more impersonal the relationship, but also the less arbitrary the entitlement (Corti et al., 2010). The core message of his book is that much of our social capital is embedded within any kind of network around us. Guanxi though, does not confer benefits or obligations simply by membership in a social network. A father may introduce his son; he is afforded an opportunity for membership. But the son must prove himself through his attitude to other members and his willingness to endure, Chiku Nailao and the engage in the other behaviours discussed earlier that give guanxi its substance (Solinger, 1987).

Bourdieu's concept of social capital differs from Coleman's concept. Coleman (1988) approached the concept of social capital in the context of family and community. He examined the relationship between social capital and the probability of academic failure. For Coleman, social capital consists of different entities, comprising social structures that facilitate certain actions and which provide a basis for interacting with other social structures (Coleman, 1988). Social capital is different from physical capital or human capital; it is a public good, open to the limited public or membership of the community, derived from specific social structures, that is profitable to individual interests. So the academic failure may be cushioned from the abject denigration that could occur to him in the wider community. Similar safeguards are available within guanxi, though the academic failure will not be engaged in functions for which he is not ostensibly able. That is, while there may be some degree of nepotism, it will not extend to bolstering incompetence that has damaging consequences for the entire social network.

Nahapit and Ghoshall (1998) defined social capital as "the sum of the actual and potential resources embedded within, available through and derived from the network of relationships possessed by an individual 
or social unit" to achieve holistic benefits from combining social capital, intellectual capital and organizational advantage. Thus social capital generates creation of new intellectual capital; organizations, including those based on relationships like guanxi, as well as organisations like firms are able to form denser social capital over competitors (Jun and Si, 2010). In this respect, guanxi will be applied whereby Chinese social networks act collectively and competitively to attract new members who enhance their networks. They do not induct new members simply because of acquaintance, but because of the benefits to be derived from their admittance.

Putnam et al. (1994) notion of social applies to development studies and so has particular application to guanxi as it applies to China as a developing economy. Putnam et al. (1994) addresses conditions for creating strong, responsive and effective institutions in different regions in Italy, where similar social networks to those in rural China existed until recently. Putnam stresses the role of association for the generation of an informed, if closed, public as a necessary condition for a healthy civic community. Social capital by the degree of participation in social activities within sports and cultural associations. Putnam et al. (1994) identifies limitations on such participation in that social capital diminishes where there is distrust, conflicting norms, or where social networks compete with each other. While Italian villages seek to minimise barriers to social participation, the Chinese guanxi may different aims and even different values. The members of guanxi come together from various groups in order to achieve identified common goals whether commercial, social or political.

Fukuyama (1995a, 1995b) attempts to explain reasons for some countries being more economically successful than others, extending beyond the village level of Putnam. But like Putnam, Fukuyama (1995a, 1995b) treats social capital as trust, together with the capacity for cooperation. He concludes that high levels of sociability or social capital and loyalty enable individuals work cooperatively in the corporations collectively propel an economy towards prosperity. Though these corporations compete with one another, the internal culture, that reflects the trust and cooperative spirit found in guanxi, ensures the internal efficiency and productivity necessary for them to compete with rivals while contributing to the broader community.

In sum, social capital is argued from various sources. Firstly, much of social capital is embedded within networks of mutual acquaintance and recognition. Secondly, social capital is available through the contacts or connections networks bring. Thirdly, social capital can be derived from membership in specific networks, where such a membership is restricted (Nahapiet and Ghoshal, 1998). In short, from the variety of definitions of social capital, it is concluded that social relationships are a common element, as Astone et al. (1999) find, the use of term social capital to refer to the resources that emerge from one's social ties is exceedingly popular.

\section{CONCLUSION}

To conclude, guanxi and social capital are similar concepts. They overlap markedly in Coleman's social capital $(1988,1990)$ theory. But it is distinct from that of Loury (1977) in whose view social capital is limited by family relations and in community social organization. Lin (1982) defines his concept social resources as resources embedded in one's social network, overlooking the interconnectedness of dyads that form ongoing networks beyond the individual. Granovetter (1973; 1974) was concerned with how social relationships are instrumental for achieving goals. Coleman (1988; 1998) has identified the limitations of levels of social relations within the family or beyond, so that successful dyadic relations, as in guanxi, extend out from a core into a series of concentric relationships to provide social capital. Nonetheless, social capital and guanxi are not interchangeable terms. The two are distinguished in that social capital embraces the attributes of individuals (Coleman, 1988; 1998; Putnam et al., 1994); guanxi applies to series of dyadic interpersonal relationships, not readily transferred into a hierarchical organization focused on a central or core competency. Yet like guanxi, the social capital of Bourdieu (1986) is not necessarily a natural given: it results from investment by individuals striving to form beneficial social relations, but with the focus on their own inputs rather than reciprocal gain.

\section{REFERENCES}

Astone, N.M., C.A. Nathanson, R. Schoen and Y.J. Kim, 1999. Family demography, social theory and investment in social capital. Population Dev. Rev., 25: 1-32. DOI: 10.1111/j.1728-4457.1999.00001.x

Bernardes, E.S., 2010. The effect of supply management on aspects of social capital and the impact on performance: A social network perspective. J. Supply Chain Manage., 46: 45-55. DOI: 10.1111/j.1745-493X.2009.03185.x

Bian, Y.J., 1994. Work and inequality in urban China. 1st Edn., State University of New York Press, New York, ISBN-10: 0791418014, pp: 286. 
Bourdieu, P., 1986. The Forms of Capital. In: Handbook of Theory and Research for the Sociology of Education, J.G. Richardson (Ed.). Greenwood Press, New York, pp: 241-265.

Buckley, P.J., J. Clegg and H. Tan, 2006. Cultural awareness in knowledge transfer to China-The role of guanxi and mianzi. J. World Bus., 41: 275-288. DOI: 10.1016/j.jwb.2006.01.008

Burt, R.S., 1992. Structural Holes: The Social Structure of Competition. 1st Edn., Harvard University Press, Cambridge. MA, ISBN-10: 0674843711, pp: 324.

Carifio, J. 2010. Development and validation of a measure of relational leadership: implications for leadership theory and policies. Current Res. Psychol., 1: 16-28. DOI: 10.3844/crpsp.2010.16.28

Chen, X.P. and C.C. Chen, 2004. On the intricacies of the chinese guanxi: a process model of guanxi development. Asia Pacific J. Manage., 21: 305-324. DOI: 10.1023/B:APJM.0000036465.19102.d5

Chueng, T.S. and A.Y. King, 2004. Righteousness and profitableness: The moral choices of contemporary confucian entrepreneurs. J. Bus. Ethics, 54: 243-257. DOI: $10.1007 /$ s10551-004-6405-6

Coleman, J.S., 1988. Social capital in the creation of human capital. Westerner J. Sociol., 94: 95-120. http://www.jstor.org/stable/2780243

Coleman, J.S., 1998. Foundations of Social Theory. 1st Edn., Belknap Press of Harvard University Press, Cambridge, ISBN-10: 0674312260, pp: 1014.

Corti, I.N., P.N. Marola and M.B. Castro, 2010. Social inclusion and local development through european voluntourism: A case study of the project realized in a neighborhood of morocco. Am. J. Econ. Bus. Admin., 2: 221-231. DOI: 10.3844/ajebasp.2010.221.231

Fan, Y., 2002. Questioning guanxi: definition, classification and implications. Int. Bus. Rev., 11: 543-561. DOI: 10.1016/S0969-5931(02)00036-7

Fukuyama, F., 1995a. Social capital and the global economy. Foreign Affairs, 74: 89-103. http://www.jstor.org/stable/20047302

Fukuyama, F., 1995b. Trust: The Social Virtues and the Creation of Prosperity. 1st Edn., Free Press, London, ISBN-10: 0684825252, pp: 480.

Gao, H., D. Ballantyne and J.G. Knight, 2010. Paradoxes and guanxi dilemmas in emerging Chinese-Western intercultural relationship. Ind. Mark. Manage., 39: 264-272. DOI: 10.1016/j.indmarman.2008.11.001

Graham, J.L. and N.M. Lam, 2003. The Chinese negotiation. Harvard Bus. Rev., 81: 82-91. http://www.cccb.org.uk/Chinese_Chamber_Comm erce_in_Britain_Resources/files/Harvard\%20Busin ess\%20Review\%20-

\%20The\%20Chinese\%20Negotiation.pdf
Granovetter, M., 1973. The strength of weak ties. Am. J. $\quad$ Sociol., $\quad$ 1360-1380. http://smg.media.mit.edu/classes/library/granovette r.weak.ties/granovetter.html

Granovetter, M., 1974. Getting A Job: A Study of Contacts and Careers. 1st Edn., University Of Chicago Press USA., ISBN-10: 0226305813, pp: 259.

Guthrie, D., 1998. The declining significance of guanxi in China's economic transition. China Q., 154: 254-282. http://www.jstor.org/stable/655891

Guthrie, D., 2002. Information Asymmetries and the Problem of Perception: The Significance of Structural Position in Assessing the Importance of Guanxi in China. In: Social Connections in China: Institutions, Culture and the Changing Nature of Guanxi, Gold, T., D. Guthrie and D. Wank (Eds.). Cambridge University Press, Cambridge, pp: 37-53.

Ho, C. and K. Redfern, 2010. Consideration of the role of guanxi in the ethical judgments of chinese managers. J. Bus. Ethics, 96: 207-221. DOI: 10.1007/s10551-010-0459-4

Ho, D.Y.F., 1976. On the concept of face. Am. J. Sociol., $\quad 81$ : 867-884. http://www.jstor.org/pss/2777600

Hong, J. and Y. Engestrom, 2004. Changing principles of communication between chinese managers and workers confucian authority chains and guanxi as social networking. Manage. Commun. Q., 17: 552-585. DOI: $10.1177 / 0893318903262266$

Jacob, J.B., 1979. A preliminary model of particularistic ties in Chinese political alliances: Kan-ching and Kuan-his in a rural Taiwanese township. China Q., 78: 237-273. http://www.jstor.org/stable/652955

Lin, J. and S.X. Si, 2010. Can guanxi be a problem? Contexts, ties and some unfavorable consequences of social capital in China. Asia Pacific J. Manage., 27: 561-581. DOI: 10.1007/s10490-010-9198-4

Lin, N., 1982. Social Resources and Instrumental Action. In Social Structure and Network Analysis, Marsden, P.V. and N. Lin (Eds.), Publications, London, pp: 131-146.

Loury, G., 1977. A Dynamic Theory of Racial Income Differences. In: Women, Minorities and Employment Discrimination, Wallace, P.A. and A.M. LaMond, (Eds.). Lexington Books, USA., pp: 153-188.

Luo, Y. and M. Chen, 1996. Managerial implications of guanxi-based business strategies. J. Int. Manage., 2: 293-316.

Luo, Y., 2007. Guanxi and Business. 2nd Edn., World Scientific Publishing Compan, India, ISBN-10: 9812700463, pp: 412. 
Nahapiet, J. and S. Ghoshal, 1998. Social capital, intellectual capital and the organizational advantage. Acad. Manage. Rev., 23: 242-266. DOI: $10.2307 / 259373$

Park, H.S. and Y. Luo, 2001. Guanxi and organizational dynamics: Organizational networking in Chinese firms. Strategic Manage. J., 22: 455-477. DOI: $10.1002 / \mathrm{smj} .167$

Perks, H., K. Kahn and C. Zhang, 2009. An empirical evaluation of $\mathrm{R}$ and D-Marketing NPD integration in chinese firms: The guanxi effect. J. Product Innovation Manage., 26: 640-651. DOI: 10.1111/j.1540-5885.2009.00689.x

Putnam, R.D., R.L. Raffaella and Y. Nanetti, 1994. Making Democracy Work:Civic Traditions in Modern Italy. 1st Edn., Princeton University Press, Princeton, ISBN: 0691037388, pp: 280.

Pye, L.W., 1992. Chinese Negotiating Style: Commercial Approaches and Cultural Principles. 1st Edn., Quorum Books, Wespot, CT, USA., ISBN-10: 0899307248, pp: 119.

Rosato, D.V., 2005. Plastics China: Technologies, Markets and Growth Strategies to 2008. Ist Edn., Elsevier Science, USA., ISBN: 1856174441, pp: 248.

Solinger, D.J., 1987. Chinese Business Under Socialism: the Politics of Domestic Commerce in Contemporary China. 1st Edn., University of California Press, London, ISBN-10: 0520061810, pp: 400.
Standifird, S.S. and R.S. Marshall, 2000. The transaction cost advantage of guanxi-based business practices. J. World Bus., 35: 21-42. DOI: 10.1016/S1090-9516(99)00032-2

Tsang, E.W.K., 1998. Can guanxi be a source of sustained competitive advantage for doing business in China? The Acad. Manage. Executive, 12: 64-73. http://www.jstor.org/stable/4165458

Wong, Y.H. and J.L.M. Tam, 2000. Mapping relationships in China: Dynamic approach. J. Bus. Ind. Mark., 15: 57-73. DOI: 10.1108/08858620010311557

Yamagishi, T. and M. Yamagishi, 1994. Trust and commitment in the United States and Japan. Motiv. Emot., 18: 129-166. DOI: 10.1007/BF02249397

Yang, M.M.H., 1994. Gifts, favors and banquets: The art of social relationships in China. 1st Edn., Cornell University Press, Ithaca, NY, ISBN-10: 080149592X, pp: 370.

Zhuang, G., Y. Xi and A.S.L. Tsang, 2010. Power, conflict and cooperation: The impact of guanxi in Chinese marketing channels. Ind. Mark. Manage., 39: 137-149.

DOI: 10.1016/j.indmarman.2008.07.002 